
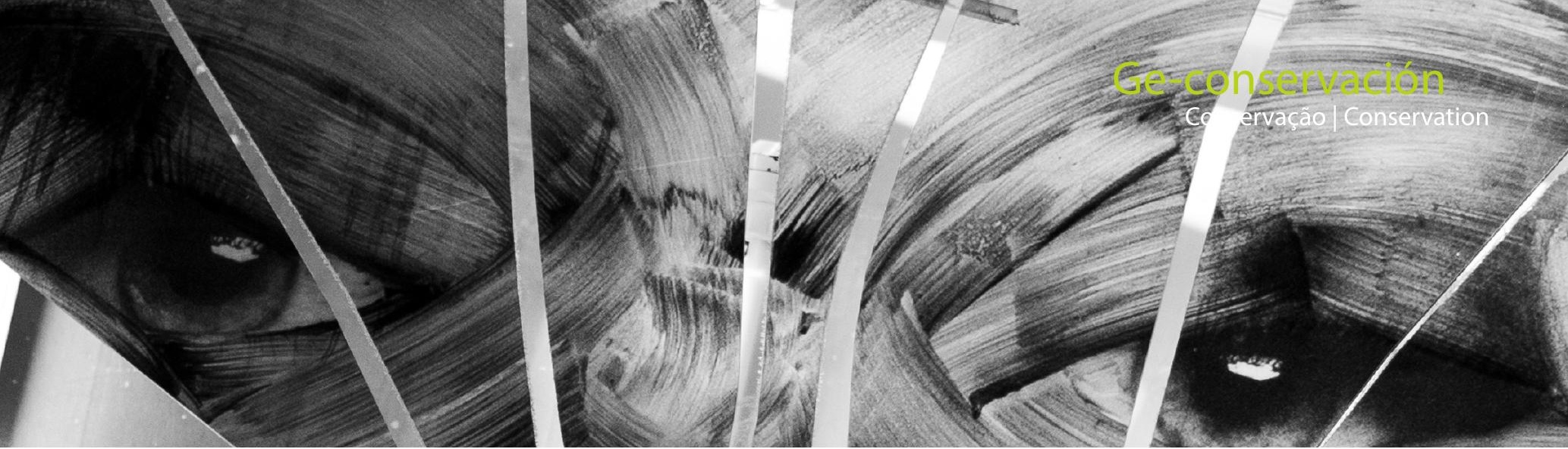

\title{
Arte urbano expuesto: procedencia, contenido e implicación
}

\author{
Elena Calderón Aláez
}

\begin{abstract}
Resumen: Análisis de dos exhibiciones de gran formato llevadas a cabo en los últimos años, dedicadas a exponer graffiti y arte urbano. Los dos casos de estudio serán: The Haus (Berlín, 2017) y Banksy: Genius or Vandal? (Madrid, 2019). Exhibiciones efímeras o itinerantes, no autorizadas o comisariadas por los propios artistas, gratuitas o privadas. Dos propuestas muy diferentes, que exponen obras de muy diversas tipologías y formatos, pero siempre englobadas bajo el título de "graffiti" o "arte urbano". En un museo tradicional, el contenido de su colección es lo que define su tipología. En este caso en nuestra clasificación, las exposiciones no son definidas o clasificadas atendiendo al contenido de la colección (materiales, soportes, técnicas, formatos), sino a la procedencia de las piezas expuestas (expoliadas del espacio público, vendidas por el propio artista, parte de colecciones privadas, creadas ex profeso (in situ o en taller, por los propios artistas...) Todas estas exhibiciones muestran un mismo tipo de expresiones artísticas provenientes del espacio público, pero cada una de ellas ha sabido exponerlo de un modo muy diferente. Analizaremos cuál es el más correcto o adecuado, atendiendo a las características del propio arte y sobre todo, a la opinión de los artistas.
\end{abstract}

Palabras clave: Banksy, The Haus, graffiti, no autorizado, arte urbano, exposición, procedencia, implicación

\section{Urban art exposed: provenance, content and implication}

Abstract: Analysis of two large-scale exhibitions in recent years, dedicated to graffiti and urban art. The two case studies will be: The Haus (Berlin, 2017) and Banksy: Genius or Vandal? (Madrid, 2019). These were ephemeral exhibitions, itinerant, unauthorized, curated by the artists, free, private ... Two very different approaches, which exhibited works of very different types and formats, but always under the title of "graffiti" or "urban art." In a traditional museum, the content of its collection is what defines its typology. In this case, in our classification, the exhibitions were not defined or classified according to the content of the collection: materials, media, techniques, formats; but to the origin of the exhibited pieces: pillaged from public space, sold by the artists themselves, part of private collections, created ex profeso (in situ or in workshop) by the artists themselves ...) All of these exhibitions show similar types of artistic expressions from the public space, but each one of them has exposed it in a very different way. We will analyze which are the most correct or adequate, taking into account the characteristics of the art itself and especially the opinion of the artists.

Key words: Banksy, The Haus, graffiti, unauthorized, street art, exhibition, provenance, implication

\section{Introducción}

En caso de que se quisiera llevar el arte urbano a los museos, ¿cuáles serían las condiciones, metodologías y factores más adecuados o correctos, teniendo en cuenta los principios fundamentales o características de este tipo de arte?

El arte urbano, para considerarse como tal, debe ser público e independiente y debe provenir del contexto de la "calle". Las técnicas y materiales empleados no son en este aspecto tan importantes, ya que hoy en día no todo se reduce al spray, plantillas (stencils) o paste-up. Además, debemos tener en cuenta que no toda la obra de los artistas urbanos se reduce al trabajo de calle, sino que también mucha parte de su producción es obra de estudio y por tanto el contexto o entorno (del que siempre se hace hincapié en las obras públicas) desaparece.

La situación ideal para llevar a cabo una exposición de estas características sería:

- Si el artista sigue vivo, ante todo, lo más importante sería contar al menos con la aprobación de éste.

- Residencia artística de larga duración en caso de que 
el artista no fuese nativo de esa localidad (contrario al denominado artista "paracaidista", que desconoce totalmente el contexto en el que trabaja y que reside en el lugar por un periodo de tiempo muy limitado).

- Creada por los propios artistas (artista-curator) o por un profesional en el ámbito indicado.

- Precio de la entrada gratuito, para que sea pública y totalmente accesible a toda la población.

- Que trabaje o tenga algún tipo de conexión con el contexto o el entorno de ese mismo lugar.

Todos estos puntos parecen bastante obvios, aun así, desgraciadamente no siempre se cumplen. Por otro lado, encontramos otros aspectos en los que aún existe debate, como los enumerados a continuación:

- ¿Cuál debería ser la duración más adecuada para las obras?, ¿es ideal que su vida sea efímera, como las de The Haus, y que todas las piezas sean destruidas al finalizar?, ¿se debería guardar algún testimonio para la posteridad?

- El tipo de obras, los materiales y técnicas empleadas no son juzgadas por ser unas más usadas que otras en el ámbito callejero, pero sí deberían jugar con el entorno y el contexto del lugar de exhibición.

- En cuanto a la ubicación y el diseño, ¿da igual si son expuestas en pequeñas galerías o en grandes pabellones?, ¿ubicadas tanto en el centro como en las afueras de la ciudad?, ¿itinerantes?, ¿únicas?

- Sobre la procedencia de estas piezas, ¿qué sería lo más adecuado?, ¿y para quién?, ¿deberían ser piezas expoliadas del espacio público, vendidas por el propio artista, parte de colecciones privadas, creadas ex profeso (in situ o en taller) por los propios artistas...?

Se espera que una exposición de arte, y más de este tipo, siempre genere algún tipo de conflicto o discusión. Hay muchas voces que piensan que exhibiciones como éstas "domestican" el arte urbano, que la subversión de este tipo de arte desaparece, que el arte urbano se contradice al introducirse en un entorno "limpio" como es una sala de exposiciones.

Se entiende que la emoción que este arte transmite, emana del hecho de que en su hábitat natural, la calle, entra de forma espontánea en comunicación con su entorno, se involucra con lo dado, lo ataca, lo mira con ironía, se burla de las cosas. En resumen, el Street Art prospera y evoluciona en resistencia con su propio entorno (incluso en su forma legal como un trabajo comisariado). Esta sensación es algo que se pierde en el museo, pero éste no es un problema nuevo en el mundo del arte. Las imágenes de un altar medieval también se descontextualizan de forma radical cuando son retiradas de una iglesia. En este caso no ahondaremos en la cuestión de si es lícito exponer en interior obras inicialmente destinadas al exterior, ya que el origen de las obras seleccionadas para estas exposiciones, aunque es muy diferente entre ambas, no ha sido en ningún momento la calle, sino que los artistas escogidos son artista urbanos, muralistas o escritores de graffiti.
Por ello, debemos tener en cuenta que algunos de los artistas en cuestión tienen también una práctica en interior, y que estas dos prácticas pueden ser del todo compatibles.

En este artículo se revisarán distintos formatos que pueden ser útiles a la hora de exponer este tipo de obras de "interior" a través de dos exposiciones muy diferentes entre sí, una como ejemplo de buena práctica y otra como ejemplo de algo que creemos debería cambiar en el mundo del arte. No contar con el consentimiento del artista es algo que no se debería permitir, pero tal y como veremos a continuación, en la exposición dedicada a Banksy, esto no es algo que preocupe a coleccionistas o curators que creen firmemente que, habiendo adquirido las obras, tienen todo el derecho de exponerlas cómo y cuándo les plazca.

\section{The Haus}

The Haus, Berlin Art Bang (Berlín, 2017) es la exhibición escogida en este artículo para ejemplificar un buen uso o práctica de la labor curatorial en el denominado arte urbano o de obras realizadas por grafiteros/artistas urbanos. Esto se debe a que fueron los propios artistas los que organizaron la muestra y la entrada era totalmente gratuita, por tanto, accesible a todo el público. Un total de ciento sesenta y cinco artistas internacionales participaron en este gran proyecto ubicado en un banco en desuso de Berlín (en el número 68 de Nürnberger Straße, en la zona conocida como Ku'Damm, avenida de Kurfürstendamm) que iba a ser demolido en pocos meses. El resultado fue la intervención de ciento ocho habitaciones en un edificio de cinco pisos (10.000 metros cuadrados) que contó con el trabajo de creadores provenientes de más de veinte países diferentes. El proyecto comenzó en enero del 2017 y la exposición estuvo abierta al público durante ocho semanas, entre los meses de abril y mayo, hasta que en junio del 2017 se clausuró antes de su demolición.

Definitivamente, la riqueza en la diversidad de materiales, formatos y contenidos, hicieron deThe Haus una exposición única que supuso un antes y un después para los entusiastas tanto del graffiti como del arte urbano y del arte actual en general. Una exposición sólo accesible por un periodo de tiempo limitado que atrajo un total de setenta y ocho mil visitantes, amantes del arte urbano, que viajaron a la capital alemana exclusivamente para no perderse una de las exhibiciones más revolucionarias de los últimos años. La responsabilidad de esta exposición recayó en un trío de creadores alemanes, activos en la escena artística urbana de Berlín durante los últimos 20 años: Kimo von Rekowski, Jörn Reiners y Marco Bollenbach, (sus alias: Kimo, Jörni y Bolle) que en conjunto forman el grupo Die Dixons. Juntos han dedicado toda su vida a pintar murales en las fachadas de la capital alemana y en otras ciudades del mundo. Además, son propietarios de la 
empresa profesional de pintura de letreros Xi-Design, que originó este proyecto. Por este motivo, tienen múltiples contactos con empresas de construcción, marcas de materiales, proveedores de pintura y pintores comerciales altamente cualificados. A raíz de este proyecto, juntos, se hacen llamar los Hausmeister (TheHaus Web). Este grupo de creadores comenzaron invitando a unos cincuenta artistas amigos, de su círculo más cercano, y en pocos días la lista de espera de artistas que deseaban tener un hueco en la exposición llegaba a los cien.

Tal vez, lo más interesante de este proyecto, aparte de la entrada gratuita, la gran implicación de cada uno de los artistas con el proyecto y la gran diversidad de propuestas, es la idea de temporalidad. Y esta idea, a su vez, proviene del concepto de trabajar en el espacio público. "Esto es lo que pasa en la calle, la obra a veces desaparece rápidamente y a veces permanece" subraya Kimo (Tuñas, 2017: s.p.).

Desde que se inició el proyecto se conocía su fecha de desaparición y caducidad, es por lo que los organizadores creen que ha tenido tanta popularidad. Cada día las colas eran infinitas, recibiendo un total de milquinientas visitas diarias para poder acceder al edificio [figura 1], ya que no más de doscientas personas podían visitar la muestra simultáneamente.

En poco tiempo, todo lo creado desapareció por completo, y convirtió la visita en única e irrepetible. "The Haus es una galería temporal y eso también tiene un impacto en la afluencia: las colas que hay en la entrada son de dos a seis horas de espera, porque esto va a desaparecer" (Tuñas, 2017: s.p.), dicen dos de los artistas invitados, Amanda Arrou-tea y Guillermo S. Quintana.

Posiblemente, debido a la naturaleza efímera de este proyecto, se podría creer en un principio que las instalacionesno serían de unaalta calidad oque suejecución sería simplemente abocetada y poco comprometida. Sin embargo, todas y cada una de las intervenciones sorprendieron gratamente por su sofisticación conceptual, destreza técnica, atención a los detalles y la originalidad

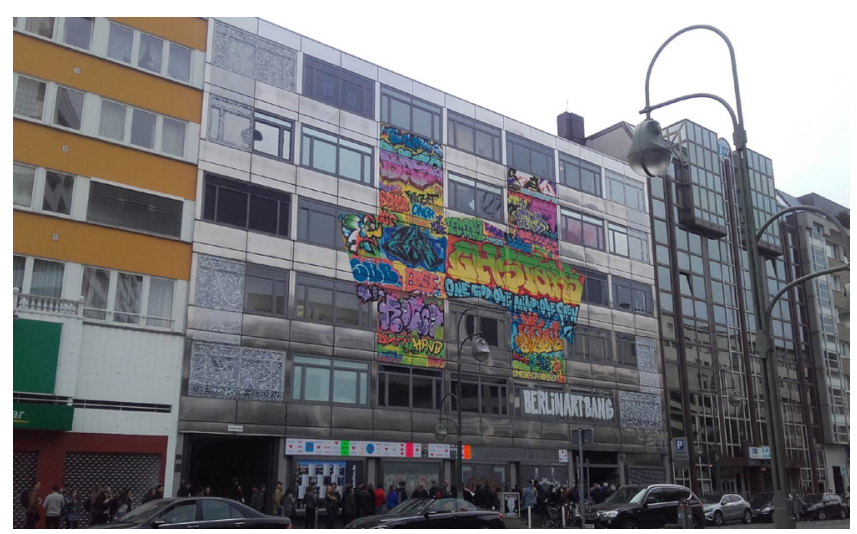

Figura 1.- Interminables colas para acceder a la exhibición de The Haus, Berlín. 6 de mayo de 2017. Fotografía de Rebeca Villanueva. de los entornos en los que el espectador se podía sentir totalmente inmerso en cada una de las habitaciones. En The Haus, se pudo apreciar todo tipo de propuestas artísticas, desde esculturas de gran tamaño, video instalaciones, graffiti, stencils, yarn bombing, fotografía, ilustración, hasta realidad aumentada. La idea no importaba, decían los creadores, "mientras fuese algo guay" (Ilovegraffiti.de Web, 2017: s.p.). Kimo explicó en uno de los tours realizados, que los conceptos de cada una de las habitaciones no están de ningún modo comisariados, simplemente pidieron algo que fuese "muy muy guay" a los artistas invitados (Rojo, 2017: s.p.).

Es cierto que algunos de los temas como: la violencia, sexualidad, trata de personas, entre otros, se repetían, pero en general cada artista plasmaba su propia visión. "No queremos problemas, ni odio, ni tonterías. Eslóganes como 'Fuck Trump' no. No queríamos este tipo de cosas. Que cada uno de ellos lo enfocase desde un punto de vista político, habría sido genial, pero era complicado, tratándose de ciento sesenta y cinco artistas en total, que sus trabajos no entrasen en conflicto. Buscábamos en todo momento llevar a cabo un proyecto familiar, nuestro objetivo era que la gente viera lo que podemos hacer, lo profesional que puede llegar a ser el arte urbano de alta calidad. Todavía se pueden hacer grandes cosas sin tener que dañar a otra gente" (Lindsay, 2017: s.p.).

En una visita guiada de dos horas por el edificio de la mano de algunos de los propios artistas, explicaban cada una de las habitaciones (10€ por persona). Uno de los detalles más curiosos y siguiendo múltiples ejemplos de la capital alemana, es que el uso de teléfonos móviles para realizar fotografías estaba totalmente prohibido y al comenzar el tour, pedían depositar los dispositivos móviles en pequeñas bolsitas grises. De este modo invitaban a disfrutar de la experiencia y olvidarse de sacar un selfie en cada una de las diferentes habitaciones. Su lema era: "At the end only the memory remains" (Estilo Palma Web, 2017: s.p.). Esta "zona sin teléfono" se creó, según expresó Kimo, para que el público "vuelva a las raíces. Use sus ojos, sentimientos y emociones, permanezca en las habitaciones. Retroceda, mire nuevamente, tóquelo. Deje de mirar las cosas a través de su teléfono o en Internet. Experiméntelo usted mismo y concéntrese en el momento" (Lindsay, 2017: s.p.). Además, con este sistema conseguían que las visitas fuesen más dinámicas y claramente tenía un punto de vista económico, pues si se deseaba tener un recuerdo del proyecto, el único modo era invertir en el catálogo creado para la muestra. De este modo, los artistas sacaban algún beneficio aparte, claro está, de donaciones o propinas de los visitantes. Este catálogo tuvo tanto éxito que se agotó en varias ocasiones, teniendo que imprimir hasta cuatro ediciones. Kimo cuenta que todo este proyecto fue posible gracias a que la inmobiliaria Pandion AG, ya que se necesitó a algún responsable que pagase el alquiler del edificio hasta que éste fuese totalmente desmantelado para transformarse en viviendas de superlujo. [figura 2] 


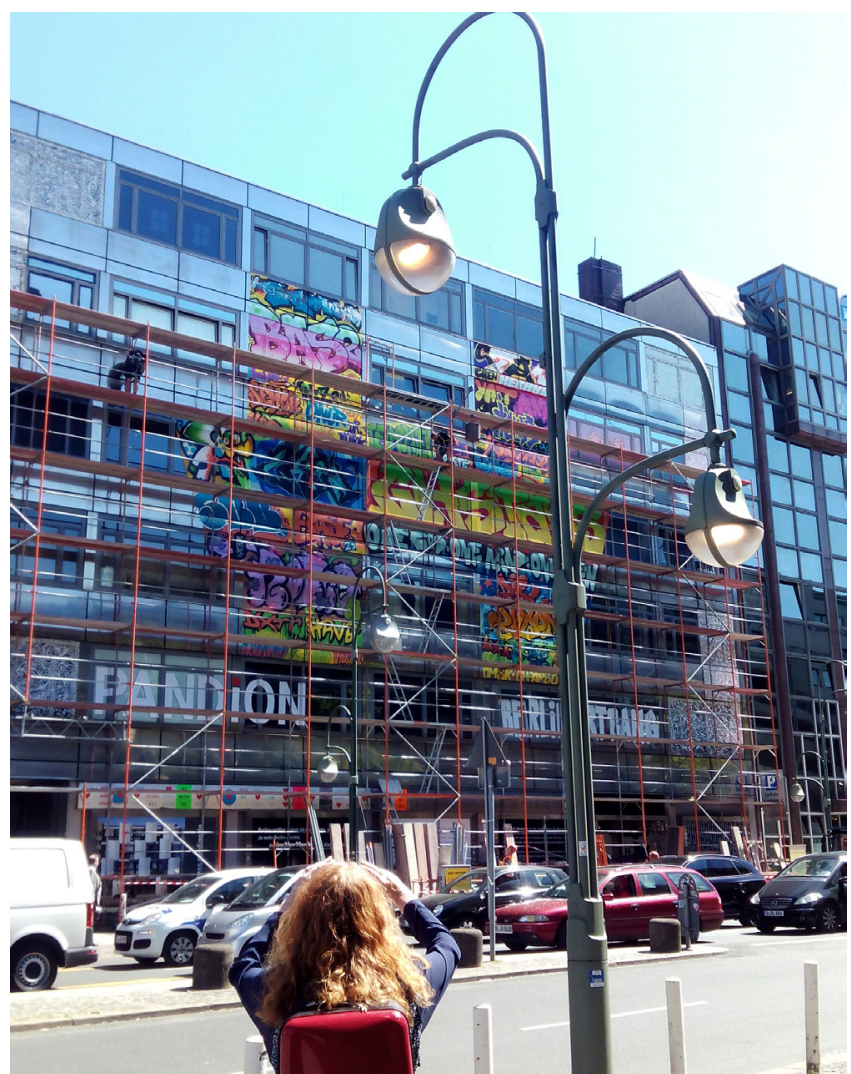

Figura 2.-La fachada, con los andamios ya colocados para su desmantelamiento, exhibe un gran grafitti de colores y la inscripción con el nombre de la inmobiliaria Pandion, Berlín. 1 de junio de 2017. Fotografía propia.

"El acuerdo fue genial para ambas partes: ellos tienen una historia que contar a sus futuros inquilinos y para nosotros era perfecto disponer de un edificio vacío en esta zona comercial de Berlín para llenarlo de Street Art". "Nos sirve para dignificar el Street Art. Nuestro arte también tiene un lugar en el centro de Berlín", añade (Tuñas, 2017: s.p.). "Recibimos las llaves de The HAUS el octubre pasado, preparamos un plan en noviembre y llamamos a todas las personas que sabíamos que serían capaces de hacer un buen trabajo. Todos somos amigos y confiamos los unos en los otros. Esto es un proyecto familiar" dice Kimo (Tuñas, 2017: s.p.).

Los artistas trabajaron desde mediados de enero hasta el 9 de marzo. Dormían, comían y construían juntos casi sin descanso. "Les dimos algunas reglas" dijo Kimo (Lindsay, 2017: s.p.). Pudimos disfrutar de un total de ciento ocho habitaciones del banco en desuso intervenidas por artistas de la talla de: 1UP, El Bocho, Klebebande, Emess, Honsar, HRVB + Vidam + Dxtr from The Weird, One Truth, Herakut, Telmomiel y Base23. Arrou-tea (una de las artistas españolas de la muestra) contó que para ella The Haus fue "algo maravilloso, me está abriendo muchas puertas. Es una familia, es una oportunidad de enseñar mi trabajo, de poder hacerme un huequecillo aquí en Berlín, de crearte una familia. Todos los artistas, los compañeros, nos apoyamos. Es maravilloso, The Haus es un punto de partida" (Tuñas, 2017: s.p.).
Fueron propuestas, que consiguieron cautivar a los visitantes, tan diversas como la del Señor Schnu que Ilenó las paredes de su habitación con 200 kg de yogur para alimentar $400 \mathrm{~kg}$ de musgo, cubriendo casi la totalidad del cuarto para criticar la doble moral del primer mundo hacia el cuidado del planeta. Colectivos alemanes tan importantes en la escena del graffiti como 1UP o Rocco und seine Brüder, en los que destaca la pintura en trenes, también tuvieron su espacio, incluso llegaron a robar un fragmento de una de las vías ferroviarias en desuso de Berlín para exponerla en su habitación junto con vídeo del proceso de extracción de la pieza.

Algo que también hizo muy interesante este proyecto fue que absolutamente todo eran donaciones de empresas solidarias. Los materiales de construcción empleados fueron aportados por una empresa de construcción local. La cerveza que se consumió por Berliner Pilsner. Un hotel de cuatro estrellas alojó a todos los artistas durante el período del proyecto, de forma gratuita. Según Kimo, "Esto no fue una broma de marketing. Queríamos respeto por los artistas, para que eligiesen lo que querían decir. Es por eso que a nadie se le pagó y nada está a la venta" (Lindsay, 2017: s.p.). Kimo dijo que "The Haus siempre ha sido nuestro objetivo final: un espacio en el que reunir a nuestra gente, demostrar toda nuestra experiencia y crear algo grande desde el corazón, y no del bolsillo de un cliente" (Tuñas, 2017: s.p.).

Parece que de algún modo lo consiguieron y es que, aunque no deje de tratarse de un negocio más, han atendido siempre a las necesidades de los artistas dándoles a todos la misma oportunidad y han conseguido transformar un edificio bancario en una iniciativa artística.

Muy al contrario de lo que ocurrió, como veremos a continuación, en la exposición de Banksy en Madrid, ya que la propia exhibición se convirtió en un negocio redondo.

\section{Banksy}

La exposición titulada "BANKSY: Genius or Vandal?" (Madrid, diciembre 2018 - mayo 2019), ha sido la primera gran muestra en España sobre el artista británico. Albergada en el ESPACIO 5.1 de IFEMA, mostraba un total de setenta obras originales cedidas por coleccionistas privados internacionales.

"Una impresionante instalación audiovisual envolvente especialmente creada para esta muestra dará la bienvenida al visitante, desvelando pistas sobre el misterioso artista, destacando sus piezas más importantes y enmarcando su insólita trayectoria, no exenta de polémica". (BANKSY: Genius or Vandal? Web oficial). Así es como vendían la exposición, ya que, de algún modo, tenía que justificar el desorbitado precio de la entrada. [figura 3]

Alexander Nachkebiya, comisario responsable de la exposición, decía: "Queremos que cada visitante de esta 


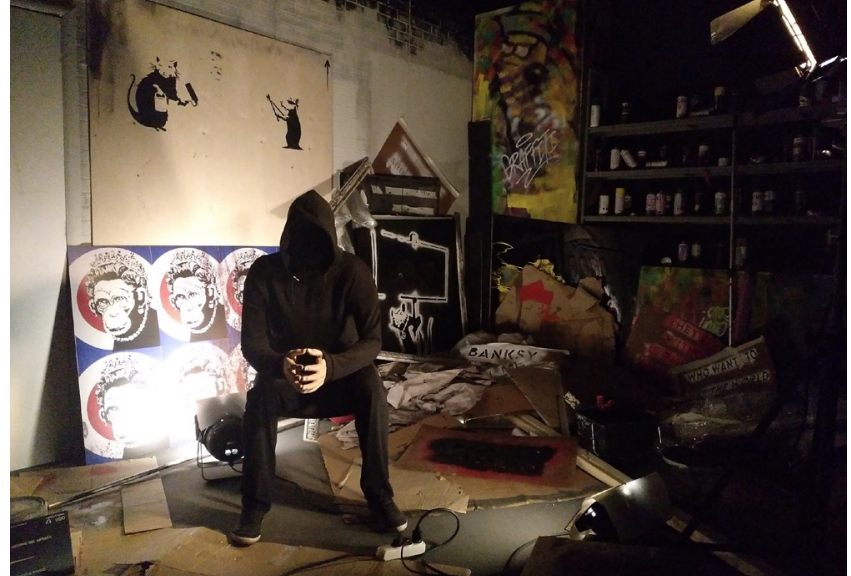

Figura 3. Ejemplo de instalación dentro de la exposición simulando la grabación del documental de Banksy: Exit Through The Gift Shop. Madrid, 8 abril de 2019. Fotografía propia.

exposición pueda resolver por sí mismo quién es realmente Banksy: ¿un genio o un gamberro?, ¿un provocador o un rebelde?". (CORES, 2017: s.p.).

Organizada por las empresas IQ Art Management y Sold Out, llegó como exposición itinerante tras haber pasado con gran éxito por las ciudades de Moscú y San Petersburgo, donde fue visitada por más de quinientas mil personas.

En la web oficial de esta exposición de Madrid se indicaba que: "Esta muestra, como todas las dedicadas a Banksy anteriormente, no está autorizada por el artista, que busca defender su anonimato y su independencia del sistema". (BANKSY: Genius or Vandal? Web oficial). [figura 4]

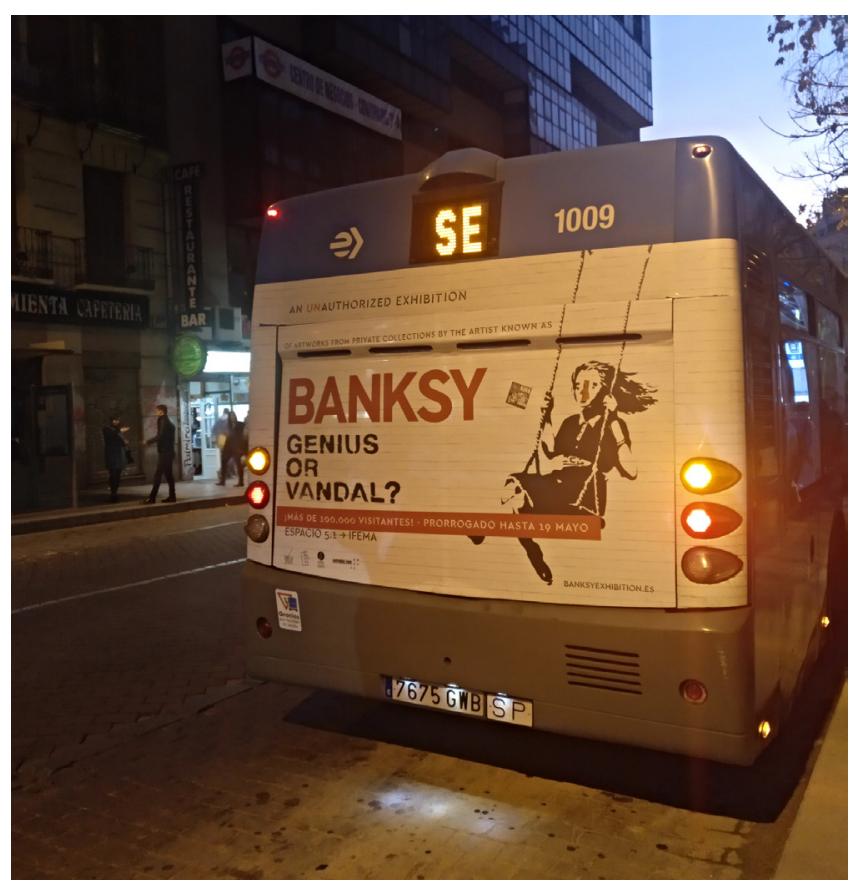

Figura 4. Publicidad de la exhibición de Bansky en el transporte público de Madrid. En la letra pequeña podemos observar que se indica en inglés: "an unauthorized exhibition". Madrid, 9 de marzo de 2019. Fotografía propia.
BANKSY: Genius or Vandal?, ésta es la cuestión principal que nos plantean sus organizadores. Para nosotros, tiene fácil respuesta. Todo el que diga que Banksy es más vándalo que genio debería visualizar su último documental The Man Who Stole Banksy (2018). En el documental queda clarísimo cómo cualquier acción que realice este artista, por mínima que sea, consigue cambiar el entorno en el que la pieza se ubica, casi de forma radical.

Se ha llegado a un punto en el que carece absolutamente de importancia el contenido de sus stencils. Ahora lo que importa es que Banksy ha intervenido en un lugar concreto y en sus últimas piezas se ha podido ver cómo todos estos lugares están elegidos a conciencia. Las intervenciones realizadas en el muro de Palestina y posteriormente la construcción de su hotel con vistas al muro, que había intervenido, han supuesto un gran cambio en su entorno y comunidad local, cosa que cualquier otra intervención con mayor contenido o trasfondo de cualquier otro artista no habría conseguido. Banksy, por tanto, ha dejado de ser el genio del contenido político y la reivindicación, para pasar a ser el genio del marketing y las redes sociales (del mainstream).

Esta exposición de Madrid, al mostrar únicamente láminas o piezas "de estudio", sólo se centra en ese contenido "político" o "reivindicativo" de las obras obviando totalmente la conexión entre la pieza y su entorno/ contexto. Conexión que sí encontramos en sus obras callejeras y por tanto, quedando muy lejos la idea que hace único a este artista. Pero esta cuestión de si se trata de un genio o un vándalo, queda obsoleta. La cuestión que verdaderamente interesa en esta muestra es: ¿se trata de arte ó es un negocio? El precio de la muestra era de 14,90 € más gastos de gestión. Niños (hasta 12 años): $7,90 €$ más gastos de gestión. Lo cual se traduce en 16,40 $€$ y $9,40 €$, respectivamente. La muestra exhibía un total de setenta obras (veintiocho obras originales y cuarenta y cinco piezas de edición limitada, que Banksy realizó en su estudio), de las cuales únicamente una es un arranque de pared. El resto son serigrafías numeradas (de tiradas larguísimas, algunas de quinientos ejemplares) que carecen de interés. Cuando llega a nuestros oídos la existencia de una exposición dedicada a un artista urbano se deduce que se van a encontrar piezas arrancadas de la calle y expuestas en un espacio cerrado. En este caso ni eso. Por ello, incluso el comisario Nachkebiya, sentía la necesidad de aclarar que: "Todo lo que hay aquí lo ha hecho Banksy con sus manos". (Pulido, 2018: s.p.)

El valor global de todas las piezas expuestas en la muestra era de 15 millones de libras. La más cara, Stop Esso, era la única obra que sí provenía del arranque de un muro del espacio público y cuyo precio es de 1,7 millones de libras [figura 5].

Se sabe que Banksy también tiene una parte de obras creadas en estudio, de tipo gráfico, y que son ideadas para exponer en interior (láminas, serigrafías...), pero 


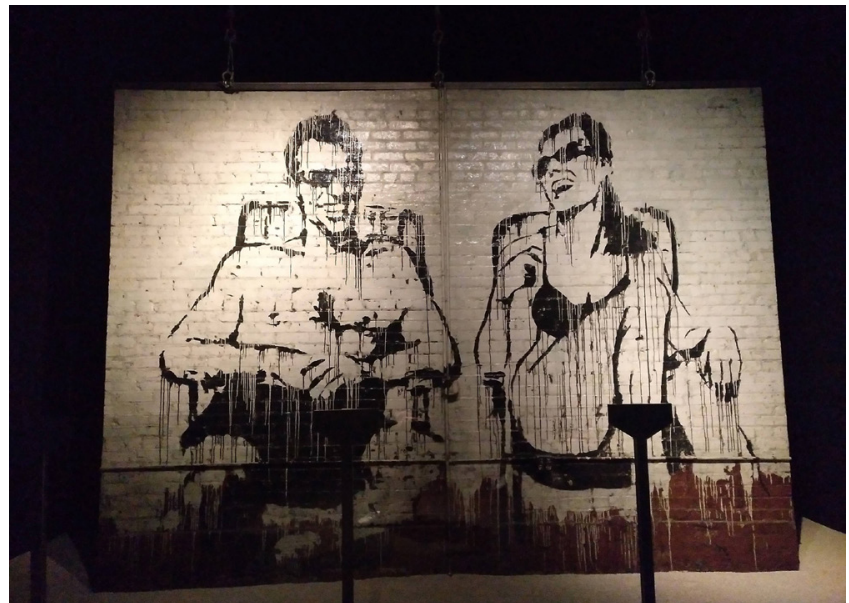

Figura 5. Stop Esso es la obra más cara de la exposición (427 por 366 centímetros), un muro cuyo precio es de 1,7 millones. Madrid, 9 de abril de 2019. Fotografía propia.

está claro que no es lo que más atrae en el caso de ir a visitar una exposición de una figura del arte urbano de su talla mediática. Resultaba curioso que la exhibición careciese de catálogo, pero este detalle hacía darse cuenta de que la propia exposición era en sí misma un catálogo sin más, sin ningún interés más que simples láminas acompañadas de una explicación de la audioguía, disponible a través de la descarga de una app. Un buen título para la muestra habría sido: "Entrada por la tienda de regalos", haciendo un guiño a su primer documental y remarcando que lo más interesante, en este caso, de la exhibición, fue la tienda ubicada a la salida del recinto, repleta de vulgar merchandising [figura 6].

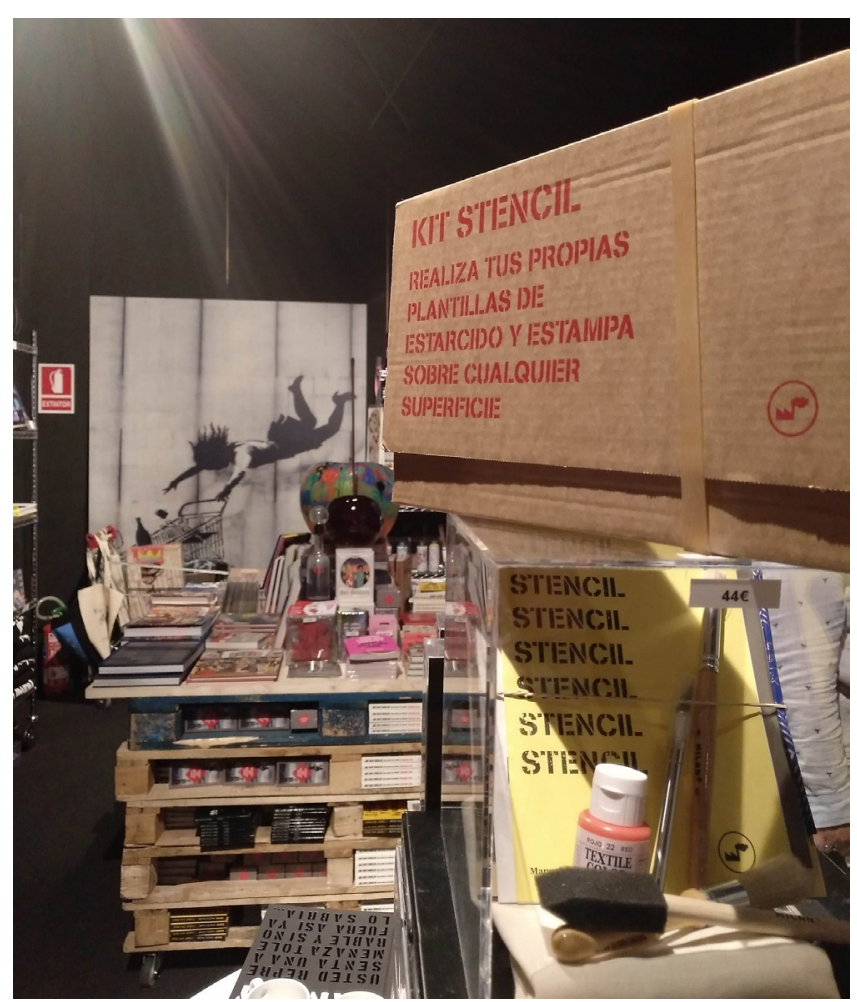

Figura 6. Ejemplo del merchandising que la tienda de la exposición ofrecía. Madrid, 9 de abril de 2019. Fotografía propia.
Las preguntas inmediatas que surgen acerca de esta exposición son ¿quién la organiza?, ¿qué relación tienen con la figura de Banksy? y por tanto ¿qué grado de implicación tiene el artista en todo esto?. La realizaron en conjunto dos empresas: IQ Art Management y Sold Out, especializadas en eventos culturales. Esta última ha celebrado exposiciones de gran tirón popular sobre David Bowie, Björk, Harry Potter o Juego de Tronos. En los últimos veinte años, Sold Out ha organizado algunos de los proyectos de entretenimiento más importantes que se han realizado en nuestro país, desde conciertos hasta obras de teatro, pasando por exposiciones, festivales y eventos corporativos. Sold Out trabaja habitualmente organizando giras y espectáculos internacionales. El pasado 17 de noviembre estrenó, también en ESPACIO 5.1, Jurassic World: The Exhibition, la exposición oficial de la exitosa saga cinematográfica (Sold out Web Oficial).

Según Rafael Giménez, socio director de Sold Out, "vimos esta exposición en Rusia hace un año. Hay tres de Banksy en el mercado, pero nos gustó ésta porque está muy bien montada y tiene obras singulares" (Pulido, 2019. S.p). Tal vez en el montaje audiovisual se pueda coincidir, pero desconocemos a qué se refería exactamente con el término "obras singulares", siendo todas ellas tiradas de serigrafías, excepto un único arranque de un mural original.

Curiosamente, el director general de IQ Art Management, Alexander Nachkebiya, es además productor y comisario de la exposición de Banksy junto con Andrew Lilley, propietario de la Lilley Fine Art/Contemporary Art Trader Gallery (Galería de Irlanda del Norte que había cedido la mayoría de las obras que se podían ver en la exposición).

En la página web oficial se especificaba que algunas de las obras estarían a la venta "incluyendo obras originales, esculturas, instalaciones, vídeos y fotografías. Las piezas, procedentes de colecciones privadas y con la colaboración de Lilley Fine Art/Contemporary Art Trader Gallery, se exhibían en España por primera vez" (BANKSY: Genius or Vandal? Web oficial).

El hecho de que algunas obras estuviesen a la venta dejaba entrever que ésto, más que de arte, se trataba de un completo negocio, por lo que el comisario de la exposición se vio obligado a aclarar que "Todo está a la venta, excepto el amor" (Pulido, 2019: s.p).

La localización elegida fue en ESPACIO 5.1, el nuevo recinto para grandes exposiciones en IFEMA [figura 7]. Este espacio se ha creado con la idea de albergar de forma regular grandes exposiciones internacionales. Se trata de una carpa permanente de $5.000 \mathrm{~m}^{2}$ anexa al edificio principal de IFEMA, pero con una entrada independiente.

En este espacio se tiene prevista la programación de dos exposiciones al año, blockbusters y títulos internacionales para todos los públicos y de temática variada, "que ofrecerán nuevas experiencias al visitante, prestando 


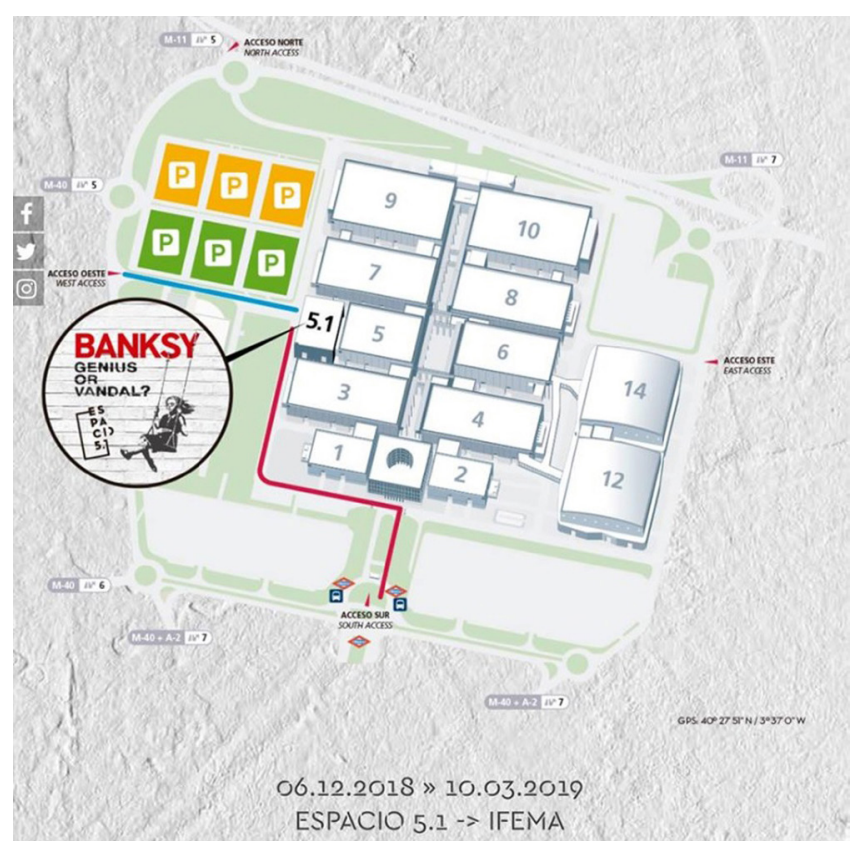

Figura 7. : Captura de pantalla, mapa de la localización de la exposición de Banksy en el Recinto ferial de Ifema, Madrid. Disponible en: https://www.banksyexhibition.es/la-exposicion/ [Consulta: 22/08/2019].

una especial atención a la inmersividad y a las nuevas tecnologías audiovisuales" (Espacio 5.1 Web Oficial).

Encontrar críticas negativas acerca de la exposición es una tarea complicada. Todas las opiniones son positivas y muy superficiales. Lo único de lo que el público se ha quejado es del excesivo precio de la entrada.

Únicamente un artículo en castellano habla de que la exposición pretende plantear un dilema a los visitantes, pero la polémica se queda en la puerta: "Dicen proponer el debate entre el público acerca de si Banksy es, como el nombre de la exposición muestra, un genio o un vándalo. Sin embargo, más allá de este título, no hay nada en las instalaciones que incentive dicho debate. Se limitan a exponer las obras junto a textos que alaban la figura del artista urbano" (Serrano, 2018, s.p.). Pero por otro lado afirma que:"De no ser por el excesivo precio, la exposición sería ciertamente recomendable". Ya que la exposición según él "ofrece un diseño y unas instalaciones francamente impresionantes" (Serrano, 2018: s.p.).

En ninguna de las opiniones aportadas acerca de la muestra se tiene en cuenta que esta exposición en ningún momento fue autorizada por el propio artista. Por tanto, lo importante sería saber qué piensa realmente el propio Banksy acerca de que sus obras sean utilizadas como excusa para que dos empresas privadas, coleccionistas y comisarios, entre otros, se beneficien económicamente. De hecho, la muestra tuvo tanto éxito en nuestro país que fue prorrogada dos meses más (de marzo a mayo del 2019).

Una exposición de arte urbano debería ser como mínimo gratis, ya que lo más interesante de este tipo de arte es que está ubicado en la calle para que sea accesible a cualquier público. Este es un principio con el que Banksy está muy de acuerdo y así lo hace saber en sus comunicados.

En su página web oficial (Banksy web oficial) Banksy se encarga de dejar bien claro cuáles de sus exhibiciones son autorizadas y cuáles no [figuras 8 y 9]. Él mismo las clasifica como "Reales" (las exposiciones que él mismo ha comisariado) o "Falsas" (en las que no ha participado en absoluto). Desde hace unos años (primera en 2016, en Estambul) se han realizado un sin fin de exposiciones no autorizadas del artista urbano Banksy en distintos países alrededor del mundo. En estas exposiciones se suele indicar que no han sido autorizadas por el artista (pero siempre en la letra pequeña) por lo que los no expertos en el ámbito del arte urbano o la galería, no siempre se percatan de este hecho (algo importantísimo a la hora de evaluar si este tipo de exhibiciones que abarcan el denominado "arte urbano", son más o menos adecuadas en cuanto al contexto de creación, adquisición de las obras e implicación del artista en ellas).

En sus descripciones, algunas de estas exposiciones, también señalan que no han sido en ningún momento ni autorizadas ni comisariadas con la ayuda del artista. Por ejemplo, en la exposición de Amsterdam en el MOCO museum se explicaba: "The 'Laugh Now' exhibition is not authorised by Banksy, nor was it curated in collaboration with the artist" (Michaut, 2019: s.p.).

Además, al lado de cada una de las exposiciones se especifica cuál es el precio de entrada de su visita, haciendo ver que las sí comisariadas por él siempre han sido totalmente gratuitas (a excepción del parque de atracciones de Dismaland por el que se cobraba un precio de 3 libras por la entrada al recinto). Los precios de las entradas a las exposiciones no autorizadas oscilan entre los 6 dólares en la de Estambul hasta los 49 dólares de la que tuvo lugar en Miami.

En la exposición de Moscú el propio comisario Alexander Nachkebiya decía: "creo que el precio de la entrada es muy justo. Hemos tratado de no sobrepasarnos con ello, era un factor muy importante para nosotros" (PYATAKOV, 2018, s.p.).

Banksy advirtió en una ocasión, en su cuenta de Instagram oficial, que él únicamente cobraría la entrada para ver su arte si hubiese una "fairground wheel" (noria). Y parece que lo ha cumplido hasta el momento, ya que sólo lo hizo en el caso del parque de atracciones. Durante los pocos meses en los que se ha redactado este artículo la lista de exposiciones no autorizadas ha crecido con otras tres ciudades europeas (Lisboa, Sicilia y Gotemburgo). En total han sido diecisiete exposiciones no autorizadas desde 2016. Desde las que tuvieron lugar en Estambul y Antwerp hasta lo que llevamos de año 2019.

El tipo de obras que se exhiben en estas exposiciones son en su mayoría de tipo "indoor" (tal y como se menciona 

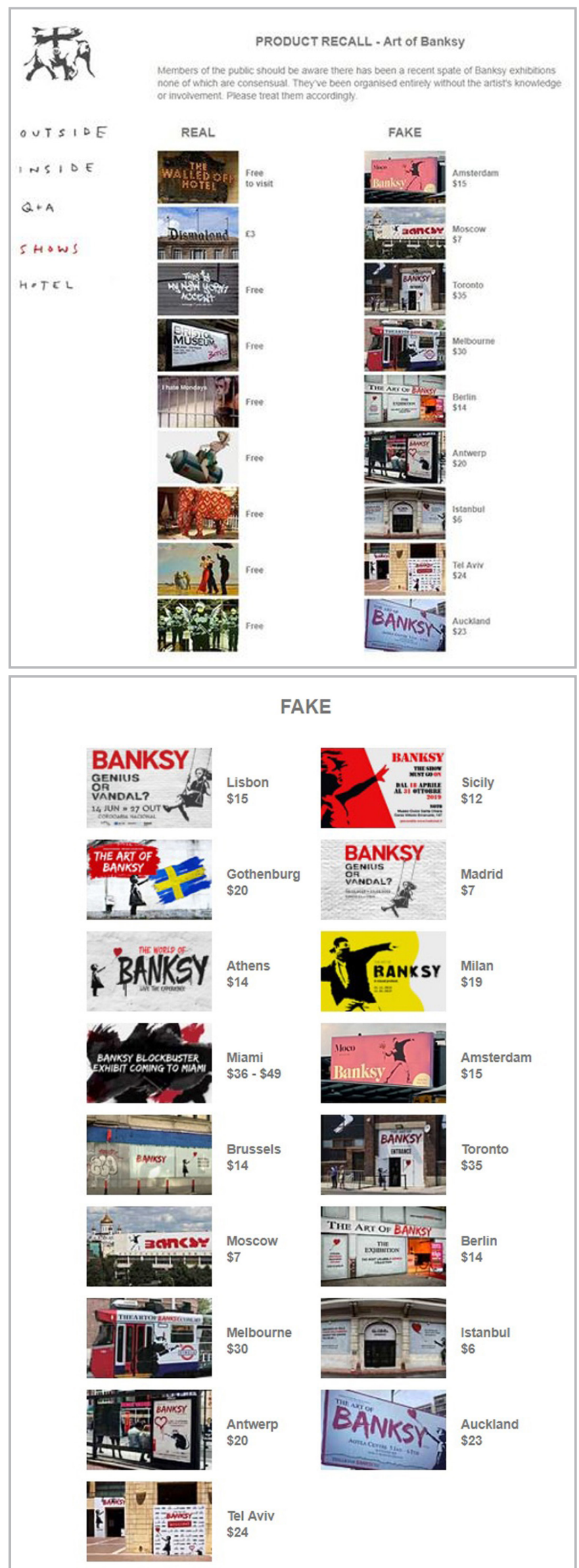

Figuras 8 y 9.- Captura de pantalla de la clasificación en su página web oficial de las exposiciones "reales" y "falsas". BANKSY WEB OFICIAL. Disponible en: http://www.banksy.co.uk/ [Consulta: 23/08/2019]. en todas las descripciones en cada una de las páginas web oficiales de dichas exposiciones), como sucedió en la de Madrid.

Lo importante en este caso, para grandes exhibiciones como éstas, es vender el nombre del artista. $Y$ en este caso concreto, Banksy es únicamente conocido por sus piezas de arte urbano. Por tanto, el público lo que busca ver en este tipo de muestras son piezas de tipo arte urbano y no simples láminas de algunos de sus stencils. Su mensaje no llega de igual manera en la calle que dentro de una galería. De alguna forma, estas exposiciones tienen que justificar la muestra $y$, por ello, en casi todas la descripción es la misma: aquí podrán disfrutar de "las piezas de interior de Banksy, trabajos únicos y originales en lienzo, madera, papel... que han sido hasta el momento exhibidos en menor medida".

Pero también es cierto que la obra callejera de Banksy representa menos de la mitad de sus trabajos. El resto son óleos, acrílicos, esculturas e instalaciones. Su mercado, en general, podría clasificarse en cuatro partes:

-Serigrafías (prints). Hay aproximadamente sesenta motivos que han sido serigrafiados en ediciones desde diez a mil ejemplares por motivo.

-Los múltiples. Son originales, acabados a mano y están hechos en series de hasta veinticinco piezas. Todos firmados y numerados por Banksy.

-Originales (unique piece), pueden ser tanto óleos o acrílicos como esculturas. Hay aproximadamente setecientad piezas únicas.

-Obras "callejeras" "urbanas". Los propios propietarios de los edificios, cuyas paredes han sido pintadas, deciden vender estas obras. Este submercado no está apoyado por Banksy y su oficina Pest Control Office no emite certificados de autenticidad.

También hay un mercado en lo que se llama Ephemera. Son los catálogos de las exhibiciones, pósteres $u$ otros items relacionados con Banksy, pero no tienen edición limitada ni firma. Es decir, en pocas ocasiones se exponen obras "arrancadas de la calle" de fachadas, paredes, muros, etc, y únicamente se exhiben piezas móviles y de pequeño tamaño creadas para ser exhibidas en interior (esculturas, lienzos, láminas, etc).

Esto es lo que escribe en su blog un visitante a la exposición de Banksy en el MOCO (Amsterdam), en el cual explica con sentimientos encontrados la relación de obras exhibidas: " $A$ medida que voy entrado a la exposición me van asaltando las dudas (...) Sin embargo, me sorprende gratamente descubrir que la gran mayoría de los trabajos en la exhibición no provienen de muros arrancados o de simples fotografías. Éstas son obras originales que van desde esculturas hasta pinturas sobre lienzo e instalaciones. Esta exposición no está autorizada, pero no me da la sensación de que con ella se haya destrozado el trabajo 
de Banksy; sin embargo, un sentimiento amargo persiste ... " (Michaut, 2019: s.p.). Por tanto, sabemos que Banksy está al tanto de todas estas exposiciones que se realizan a su costa y hace poco hizo saber de forma pública que no se muestra conforme con éstas. El pasado año (2018) se hizo viral una captura de pantalla [figura 10] de una de las conversaciones que el propio artista (o quien quiera que se encargue de las redes sociales de éste) mantuvo con una persona anónima sobre la exposición que se había inaugurado recientemente en la Casa Central de los Artistas de Moscú (Rusia), de la cual éste no tenía constancia hasta el momento. Mostró su descontento al respecto, porque además el precio de la entrada incluía una visita guiada que oscilaba entre los $7 €$ y los $18 €$. Entonces colgó en su Instagram una captura de la conversación:

-"He visto esto y he pensado en ti.

BANKSY-Eres muy divertido. ¿Qué demonios es eso?

- Una exhibición de tu trabajo en Moscú. Están cobrando 20 libras de entrada. LOL.

B- Me gustaría poder encontrarlo divertido. ¿Qué es lo contrario de $L O L$ ?

- Creo que es LOL.

$B$ - ¿Sabes que no tiene nada que ver conmigo verdad? Yo no cobro a la gente por ver mi arte...

- Ellos lo han hecho parecer auténtico. Creo que deberías hacer algo. ¿No puedes enviar una nota de prensa?

$B$ - No estoy seguro de ser la persona indicada para quejarme de la gente que sube imágenes sin pedir permiso. - No tío. Esto es el principio, es un timo. Tienes que hacer algo.

B-No sabría por dónde empezar.

- ¿Subiendo una captura de pantalla de esta conversación? $B-L O L "$

La publicación se hizo viral a las pocas horas de publicarse y cuenta con más de trescientos sesenta mil "me gusta" $y$ más de siete mil comentarios.

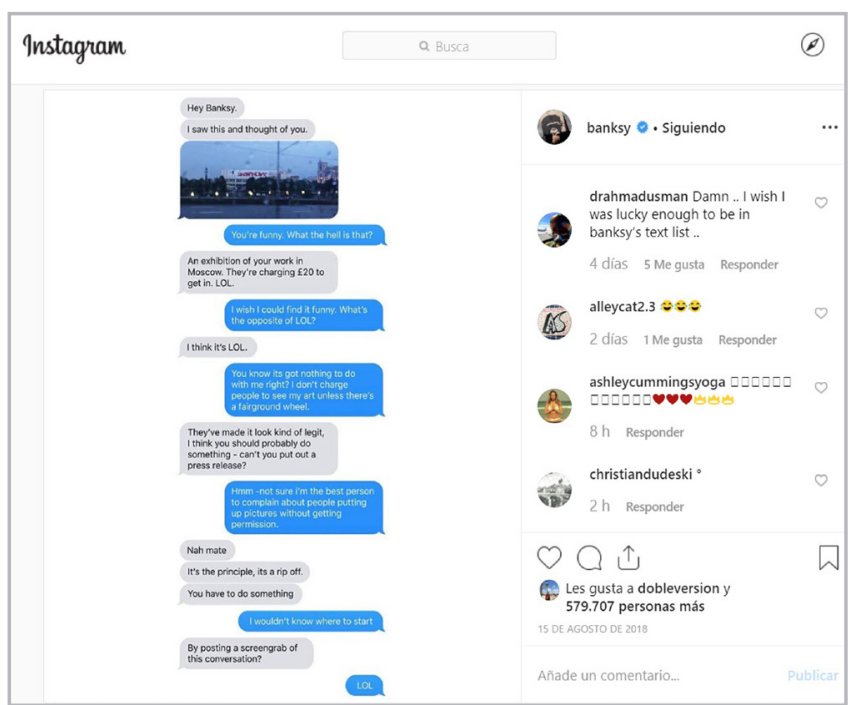

Figura 10.- Captura de pantalla de la conversación de la conversación, que Banksy publicó en su propia página oficial. Disponible en: https://www.instagram.com/banksy/?hl=es-la [Consulta: 25/08/2019].
En la conversación Banksy cuestionó su propio modus operandi, ya que él tampoco se considera como la "mejor persona para quejarse de los que suben imágenes sin tener permiso". Elena Bukhmak, una portavoz de la exposición de Moscú, tomó esta conversación como una señal de que no estaba criticando el espectáculo, a pesar de sus otros comentarios en contra. "Desde nuestro punto de vista, de esta manera, él mostró indirectamente la aprobación de nuestra exposición y está demostrando que éste también es un evento importante para él", dijo Bukhmak (Balmforth, 2018: s.p.).

Decenas de personas respondieron a la publicación de Banksy acusando a los organizadores de la exposición de Moscú de comportamiento poco ético y robo.

Respondiendo a las críticas del post, Nachkebiya dijo que Banksy nunca admite exposiciones en las que no esté directamente involucrado y generalmente emite comunicados de prensa que denuncian tales eventos.

"Creo que el hecho de que lo hiciera de una manera irónica es, en cierta medida, un reconocimiento de nuestro éxito y hace ver que fue un evento grande e importante, incluso en la carrera de Banksy", dijo Nachkebiya (Pyatakov, 2018: s.p.).

El organizador agregó: "Es realmente divertido cuando todos me preguntan acerca de la confirmación por parte de Banksy. Es decir, ¿cómo es posible obtener la confirmación de Banksy?" (Pyatakov, 2018: s.p.).

La institución rusa señaló, a través de la misma red social, que todas las obras son propiedad de coleccionistas y galerías de arte contemporáneo privadas. Apuntan que en ningún momento presentaron el evento como algo autorizado por Banksy, aun así, no tuvieron intención de retirar las piezas ya que "los propietarios tienen el derecho de exponer las obras que realizó el artista".

Además de esta clasificación entre reales y falsas, Banksy deja bien claro en su página web oficial el trato que estas exposiciones deben tener por parte del público y lo acompaña con una imagen muy ilustrativa [figura 11] que además se complementa a la perfección con su origen en el contexto urbano.

"Los miembros del público deben saber que ha habido una serie reciente de exhibiciones de Banksy, ninguna de las cuales han sido consensuadas. Han sido organizados en su totalidad sin el conocimiento o participación del artista. Por favor, trátelas en consecuencia" (Banksy Web oficial).

A la salida de la muestra, parte del personal entrega una Tablet donde se puede votar si se considera a Banksy un genio o un vándalo, pero en este caso, como bien indica Pulido en su artículo, la pregunta ideal sería "¿arte o negocio?" (Pulido, 2018: s.p.). Se podría decir que Banksy, siendo uno de los líderes en contra del sistema capitalista (hecho que parece muy alejado del espíritu de esta 


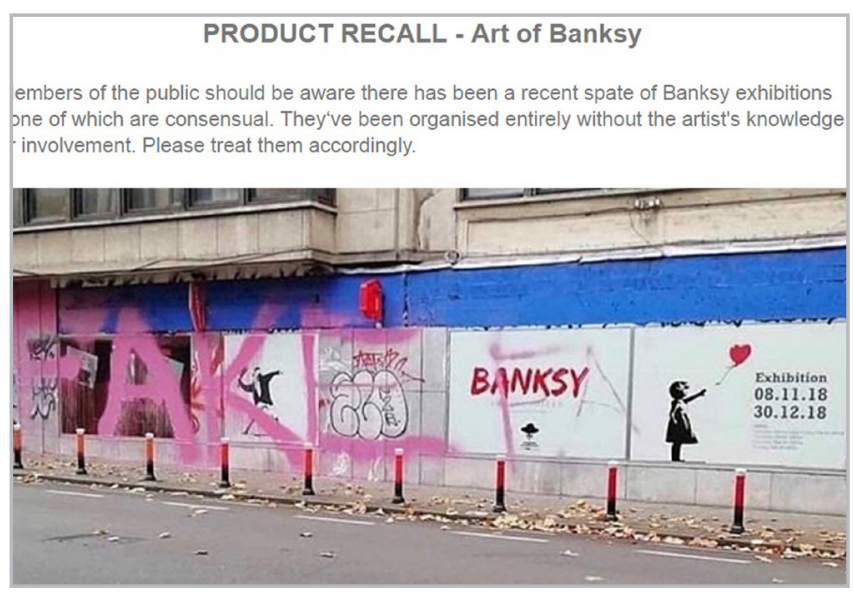

Figura 11. : En la imagen se puede ver un graffiti de gran tamaño en el que se puede leer la palabra FAKE (falso en inglés) tachando parte del advertising (publicidad) de una de sus exhibiciones no autorizadas en Bélgica. BANKSY WEB OFICIAL. Disponible en: http://www.banksy.co.uk/ [Consulta: 23/08/2019].

exposición), se ha convertido en una"víctima" de su propio éxito. $O$ tal vez se trata de un juego más, que además le aporta una publicidad desmedida. Sin embargo, sólo el artista debe ser el que tome las decisiones, al menos en casos como estos, en los que una exposición se refiere directamente a su carrera.

\section{Conclusiones}

Por tanto, lo que diferencia principalmente al formato de estas dos exhibiciones no es el precio de su entrada sino el grado de implicación que tienen cada uno de los artistas con sus piezas exhibidas.

Curiosamente estos datos son inversamente proporcionales. A mayor precio de la entrada (Banksy, Genius or vandal?, Madrid 2018-2019) menor o ninguna implicación; este es el caso de la exhibición de Banksy en Madrid. Por el contrario, cuanto menor es el precio de entrada (en el caso de The Haus, gratuito), la implicación de los artistas es mucho mayor. Como ya se vio, The Haus, era un espacio en el que cada uno de los artistas y colectivos participaron activamente creando, diseñando, dirigiendo y guiando las visitas en primera persona.

La ubicación de cada una de estas exposiciones también es un factor interesante a tener en cuenta. Ya que la de Berlín se situaba en el centro de la ciudad (pero no en una zona alternativa donde se puede encontrar mayor número de graffiti, sino en las más comerciales) mientras que la segunda se situaba en una zona alejada del centro, en la periferia, en grandes recintos de exposiciones, sin nada en común con áreas alternativas de graffiti.

La idea de temporalidad es algo que también las diferencia, mientras que la de The Haus era totalmente efímera, sin posibilidad ninguna de conservar alguna obra para el futuro, la de Banksy era una exposición itinerante con obras que aún están disponibles e incluso a la venta y ni siquiera son únicas ya que son, en su mayoría, serigrafías de largas tiradas.

Entonces para que una exposición de arte urbano sea realmente "buena"/"correcta", ¿debe ser de naturaleza efímera?. Tal vez sí, ya que la temporalidad de las obras realizadas en el espacio público es lo que atrae a estos artistas a trabajar en ellas. Debe ser gratuita y por lo tanto, pública y accesible para todo posible espectador. Y además, cuanta mayor sea la implicación del artista con el proyecto, más satisfactorio y "real" será el resultado final.

Se puede resumir que, mientras que la exposición de Banksy era: privada, con un precio de entrada desorbitado, comisariada por individuos que no tenían absolutamente nada que ver con el mundo del arte urbano o el graffiti, itinerante y con obras de "interior" (cómo era el caso de las serigrafías).

Que intentaba atraer al público a través del reclamo del "Street Art", del uso de lo "vandálico" y de la supuesta increíble puesta en escena audiovisual. Además de estar ubicada en un espacio sin personalidad en las afueras de la ciudad y de que hayan tenido lugar repetidas ediciones de la misma en diferentes ciudades alrededor del mundo.

En contraposición, la exposición de The Haus fue algo que pasará a formar parte de la historia del arte urbano y graffiti en Berlín. Situada en un edificio icónico de la ciudad, en pleno centro neurálgico de la capital, comisariada, dirigida y administrada por los propios artistas urbanos y grafiteros, con trabajos en relación con su entorno, su contexto. Además de ser totalmente gratuita, accesible para todos los públicos, con una gran variedad de propuestas artísticas, soportes, materiales y efímera.

El que sea efímera y todas las obras hayan sido destruidas al finalizar la exposición no quiere decir que sea mejor ni peor que otras, pero sí que juega y le aporta un toque romántico, que acerca más toda la muestra a la verdadera naturaleza de los trabajos creados en la calle.

Hay que destacar que, en ambas muestras, aunque tanto en una como en otra los artistas son conocidos por ser artistas urbanos y grafiteros, que realizan obras públicas, ninguna de las obras seleccionadas eran piezas ya existentes previamente, extraídas o expoliadas, de la calle. El reclamo en ambas ha sido el arte urbano y una vez más "lo vandálico", pero se ha tratado más de un trabajo de estudio (de piezas "de interior"); en el caso de Banksy, en lo que se refiere al gran número de serigrafías expuestas, y en el caso de The Haus por ser obras creadas ex profeso para la muestra (ya sea por tratarse de obra gráfica, esculturas, graffiti, murales o incluso arranque de mobiliario urbano). Quedando en ambos casos desdibujada la idea romántica y antisistema de la pureza, la frescura y la inmediatez que desprende el primigenio arte urbano. 


\section{Bibliografía}

\section{The Haus:}

ESTILO PALMA WEB. (2017) "Temporary Art: The Haus (Berlin III)". Mallorca Magazine [13 de mayo de 2017] s.p. Disponible en: https://www.estilopalma.com/2017/05/temporary-art-hausberlin-iii/[Consulta: 21/08/2019]

ILOVEGRAFFITI.DE WEB. "170 Artists Invade a Giant Empty Bank Building in Berlin - THE HAUS [PREVIEW]". [2017] s.p. Disponible en: https://ilovegraffiti.de/blog/2017/02/13/100-artists-invadea-5-storey-bank-building-in-berlin-the-haus-preview/ [Consulta: 21/08/2019]

LINDSAY. (2017) "165 Street Artists Took Over an Abandoned Building in Berlin, and the Results Are Wild" [23 de abril de 2017] s.p. Disponible en: https://www.vice.com/en us/article/3d9vg8/165street-artists-abandoned-building-berlin [Consulta: 21/08/2019]

ROJO. (2017) "ROCKING "THE HAUS": A 5-FLOOR BERLIN BANK IS TRANSFORMED BY ARTISTS" [16 de marzo de 2017] s.p. Disponible en: https://www.brooklynstreetart.com/2017/03/16/rocking-thehaus-a-5-floor-berlin-bank-is-transformed-by-artists/ [Consulta: 21/08/2019]

THEHAUS WEB OFICIAL. Disponible en https://www.thehaus.de/ [Consulta: 21/08/2019]

TUÑAS, OLALLA. (2017) "165 artistas llenan de arte un viejo banco de Berlín condenado a la demolición" [17 de mayo de 2017] s.p. Disponible en: https://www.traveler.es/viajes-urbanos/articulos/ the-haus-165-artistas-banco-berlin/10641 [Consulta: 21/08/2019]

\section{Banksy:}

BALMFORTH (2018) "Banksy calls out Moscow gallery for showing his art without approval" [16 de Agosto del 2018] s.p. Disponible en: https://www.reuters.com/article/us-art-banksy-moscow/ banksy-calls-out-moscow-gallery-for-showing-his-art-withoutapproval-idUSKBN1L11TU [Consulta: 23/08/2019]

BANKSY: Genius or Vandal? WEB OFICIAL. Disponible: https://www. banksyexhibition.es/la-exposicion/ [Consulta: 22/08/2019]

BANKSY WEB OFICIAL. Disponible en: http://www.banksy.co.uk/ [Consulta: 23/08/2019]

CORES NANI F. (2018)“La obra del misterioso e irreverente Banksy se exhibe en España por primera vez en la muestra 'Genius or Vandal?" Periódico 20 minutos. [5 de diciembre de 2018] s.p. Disponible en: https://www.20minutos.es/noticia/3508148/0/banksy-geniusor-vandal-primera-exposicion-espana-arte-urbano/ [Consulta: 22/08/2019]

ESPACIO 5.1 WEB OFICIAL. Disponible en: https://www. espacio5punto1.es/espacio-5-1/[Consulta: 23/08/2019]

MICHAUT, CHRISTOPHER. "The Writing on the Wall. Banksy's
Unauthorized Exhibition"[30 de Enero del 2019] s.p. Disponible en: http://www.dailyartmagazine.com/banksys-unauthorizedexhibition/ [Consulta: 23/08/2019]

PYATAKOV, SERGEY. "Banksy lashes out at 'unauthorized' Moscow exhibition of his work" [16 de Agosto del 2018] Disponible en: https://www.rt.com/news/436129-banksy-moscow-exhibitionsuccess/ [Consulta: 23/08/2019]

PULIDO, NATIVIDAD: “¿Por qué lo llaman arte cuando quiere decir negocio?" Periódico ABC cultura [11 de diciembre de 2018] s.p. Disponible en: https://www.abc.es/cultura/arte/abci-llamanarte-cuando-quiere-decir-negocio-201812070215 noticia.html [Consulta: 22/08/2019]

SERRANO, MIGUEL. "Banksy. Genius or vandal?» El grafitero que se creyó Robin Hood". [19 de diciembre del 2018]. Disponible en: https://eldebatedehoy.es/cultura/banksy-genius-or-vandal/ [Consulta: 23/08/2019]

SOLD OUT WEB OFICIAL. Disponible en: http://www.soldout. es/ [Consulta: 22/08/2019]

\section{Autor/es}

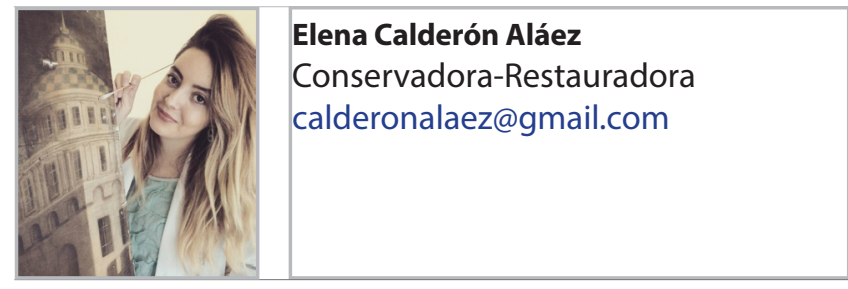

Conservadora Restauradora. Investigadora independiente.

Es Graduada en Conservación y Restauración del Patrimonio Cultural por la Universidad Complutense de Madrid. Ha sido miembro activo del grupo ST.A.CO (Street Art Conservators del TEl de Atenas) durante su beca Erasmus en Grecia (curso 2014-2015). TFG sobre conservación y restauración de obras del artista Eltono en Madrid. En el año 2017 finalizó sus estudios de Máster en Conservación y Exhibición de Arte Contemporáneo en la UPV de Bilbao. TFM sobre Artistas Urbanos intervencionistas/ apropiacionistas en España. Actualmente forma parte de la comunidad de Street Art Cities, donde documenta murales de ciudades como Bilbao, Estocolmo, Reykjavík y Maribor. 